University of South Carolina

Scholar Commons

\title{
Use of Complementary and Alternative Medicine for Weight Control in the United States
}

\author{
Patricia A. Sharpe \\ University of South Carolina - Columbia, SHARPEP@mailbox.sc.edu \\ Heidi M. Blanck \\ Joel E. Williams \\ Barbara E. Ainsworth \\ Joan M. Conway
}

Follow this and additional works at: https://scholarcommons.sc.edu/ sph_physical_activity_public_health_facpub

Part of the Public Health Commons

\section{Publication Info}

Published in The Journal of Alternative and Complementary Medicine, Volume 13, Issue 2, 2007, pages 217-222.

Sharpe, P. A., Blanck, H. M., Williams, J. E., Ainsworth, B. E., \& Conway, J. M. (2007). Use of complementary and alternative medicine for weight control in the United States. The Journal of Alternative and Complementary Medicine, 13(2), 217-222.

DOI: $10.1089 / \mathrm{acm} .2006 .6129$

(c) The Journal of Alternative and Complementary Medicine, 2007, Mary Ann Liebert, Inc.

This Article is brought to you by the Physical Activity and Public Health at Scholar Commons. It has been accepted for inclusion in Faculty Publications by an authorized administrator of Scholar Commons. For more information, please contact digres@mailbox.sc.edu. 


\title{
Use of Complementary and Alternative Medicine for Weight Control in the United States
}

\author{
PATRICIA A. SHARPE, Ph.D., ${ }^{1}$ HEIDI M. BLANCK, Ph.D., ${ }^{2}$ JOEL E. WILLIAMS, Ph.D., ${ }^{3 *}$ \\ BARBARA E. AINSWORTH, Ph.D., ${ }^{4 *}$ and JOAN M. CONWAY, Ph.D. ${ }^{5}$
}

\begin{abstract}
Objectives: The purpose was to assess the prevalence and correlates of complementary and alternative medicine use for weight control.

Design: A list-assisted random-digit-dialed telephone survey of adults was conducted in the fall of $2002(n=$ 11,211). The focus of the study was complementary and alternative medicine (CAM) use, other than dietary supplements, in the previous 12 months.

Settings/location: The sample of respondents was drawn from the total noninstitutionalized U.S. adult population residing in telephone-equipped locations.

Subjects: The sampling procedures were designed to obtain adequate representation of Hispanic and nonHispanic black respondents. Data from the total sample of 11,211 were weighted to achieve an estimate of the U.S. population. Analyses focused on 372 people who had used CAM within the previous 12 months.

Results: Of the total, 3.3\% $(n=372)$ had used a CAM therapy in the previous 12 months. Higher adjusted odds ratios for CAM use were found among respondents who were exercising for weight control; using a lower carbohydrate, higher protein diet; using a nonprescription weight-loss product(s); overweight; physically active; and not satisfied with one's body (adjusted for age, race, gender, education, and city size). The most often used therapies were yoga (57.4\%), meditation (8.2\%), acupuncture (7.7\%), massage (7.5\%), and Eastern martial arts (5.9\%). CAM users used CAM therapies on their own (62.6\%), in a group setting $(26.8 \%)$ or with a CAM practitioner $(10.6 \%)$.

Conclusions: The use of CAM therapies other than dietary supplements for weight loss was relatively low. The most popular therapy was yoga, and the majority of CAM users used CAM therapies on their own. Persons who had used other weight loss methods had greater odds for using CAM in the previous 12 months, suggesting that CAM use is often added to other weight-loss strategies.
\end{abstract}

\section{INTRODUCTION}

C Yomplementary and alternative medicine (CAM) is a group of diverse medical and health care systems, practices, and products that are not considered to be part of conventional medicine. ${ }^{1}$ Recent findings from 31,044 adults ages 18 and older on the 2002 National Health Interview Survey revealed that $36 \%$ of adults in the United States had used CAM in the previous year. When the use of prayer specifically for health reasons was added to the

\footnotetext{
${ }^{1}$ Prevention Research Center, Arnold School of Public Health, University of South Carolina, Columbia, SC.

${ }^{2}$ Centers for Disease Control and Prevention, National Center for Chronic Disease Prevention and Health Promotion, Division of Nutrition and Physical Activity, Chronic Disease Nutrition Branch, Atlanta, GA.

${ }^{3}$ Department of Psychology, University of South Carolina, Columbia, SC.

${ }^{4}$ Department of Exercise and Nutritional Science, San Diego State University, San Diego, CA.

${ }^{5}$ U.S. Department of Agriculture, Agricultural Research Service, Beltsville Human Nutrition Research Center, Diet and Human Performance Laboratory, Beltsville, MD.

*At the time the data were collected, Drs. Ainsworth and Williams were with the Prevention Research Center at the University of South Carolina.
} 
definition of CAM, CAM use was $62 \% .^{2}$ Women, persons with higher educational levels, persons who had been hospitalized in the previous year, and former smokers had relatively higher CAM use in the survey. Age showed an inverse U-shaped association, with younger and older persons using less CAM than middle-aged persons. The association of CAM use with race varied depending on the definition of CAM. ${ }^{2}$ Findings from several national surveys of CAM use reveal that in the general population, CAM use is highest among women; whites; persons of higher educational attainment and income; and persons who are widowed or divorced, middle-aged, have poorer perceived health, or live in the western United States. ${ }^{3,4}$ Persons who visit medical doctors are likely to seek out CAM practitioners concurrently, but between $63 \%$ and $72 \%$ of persons using various types of CAM do not disclose CAM use to their physician. ${ }^{5}$

Although the prevalence of CAM use for chronic medical conditions has been documented, ${ }^{2}$ little is known about the prevalence and correlates of CAM use for weight loss or weight control. In a multistate telephone survey, $7 \%$ of respondents reported using nonprescription weight loss product use (e.g., shakes, liquids, powders, and pills), ${ }^{6}$ yet little convincing evidence has been found for the effectiveness of weight loss supplements. ${ }^{7}$ No data have been published describing the types of CAM therapies used for weight control, with the exception of nonprescription dietary supplements. Given the epidemic of obesity in the United States, CAM use for weight control has significant public health implications, particularly because little research exists regarding the effectiveness of CAM therapies for weight control and existing studies have methodologic weaknesses. ${ }^{8}$ This report presents results from the National Physical Activity and Weight Loss Survey (NPAWLS) describing the prevalence and correlates of respondents' use of CAM therapies other than dietary supplements for weight control during the previous 12 months.

\section{MATERIALS AND METHODS}

The National Physical Activity and Weight Loss Survey (NPAWLS) was a nationwide telephone survey conducted between September 2002 and December 2002. Survey questions included items pertaining to overall health status and quality of life, weight-control measures, and participation in physical activity. The overall objective of the study was to obtain data on individual physical activity and nutrition risk behaviors. The sample of respondents was drawn from the total noninstitutionalized U.S. adult population residing in telephone-equipped locations. Excluded from the referent population were institutionalized adults, those living in group quarters with 10 or more unrelated residents, adults without a telephone, and adults who did not speak English or Spanish well enough to be interviewed.

\section{Sample design}

The design used a list-assisted, random-digit-dialed (RDD) sample of telephone-equipped households in the United States generated by preparing a list of all current operating telephone exchanges within each U.S. area code. These telephone exchanges, combined with all four-digit numbers from 0000 to 9999 , were divided into blocks of 100 numbers each; each block was assessed for containing at least one residential number. Qualifying blocks were combined to create the sampling frame, from which numbers were systematically drawn. Nonresidential, nonworking, fax, and modem numbers were filtered to increase the connect rate of telephone interviews with eligible respondents.

The study was designed to obtain adequate representation of Hispanic respondents and non-Hispanic black respondents. A replicate design mixing telephone numbers from three independent samples was used to achieve desired racial/ethnic percentages in the final sample. The first independent sample consisted of a national RDD draw. The second and third samples were drawn from frames constructed to yield higher percentages of Hispanic and non-Hispanic black respondents. These two samples-one targeting Hispanic households and the other targeting non-Hispanic black households-were constructed by subsetting telephone exchanges in the national frame. Telephone exchanges were included in each respective subset if ethnic household incidence was greater than $20 \%$. Ethnic household incidence was determined by area code exchange and U.S. Censusbased demographic information.

\section{Respondent selection within household}

A minimum of 15 attempts across at least 5 days was made to reach each sampled number. Interviewers first asked about the number of adults aged 18 and older in the contacted household, then asked all male and female adults in the household to be listed. The survey respondent was randomly selected from this roster. The survey had a total of 11,211 complete interviews, with a Council on American Survey Research Organizations (CASRO) response rate of $30.9 \% .^{9}$ The CASRO response rate is an outcome rate with the numerator as the number of completed interviews and the denominator as an estimate of the number of eligible units in the sample. The cooperation rate was $51.4 \%$, which is the proportion of all respondents interviewed of all eligible units ever contacted [complete interviews/(complete interviews + refusals + terminations)].

\section{Weighting}

The weights for the NPAWLS data were calculated as the product of three components: (1) a sampling weight accounting for differential probabilities of selection, defined as the inverse of the product of the household selection probability and the respondent selection probability; (2) a poststratification factor adjusting weight totals to 2000 U.S. Cen- 
sus population figures by age, race/ethnicity, and gender, computed for each of the three independent samples, with the result that the sum of the adjusted weights for each sample would produce an estimate of the eligible U.S population; and (3) a factor scaling the weights for each sample to allow for estimates based on the combined data that would not overestimate population totals.

Measures. The questionnaire was created in the format and style of the Center for Disease Control and Prevention's Behavioral Risk Factor Surveillance Survey (BRFSS), including modules covering behaviors related to diet, weight control, physical activity, and CAM use. The NPAWLS questionnaire included a module of questions to assess use of nonprescription products for weight control, such as pills, powders, and liquids. A module of questions to assess use of all other CAM therapies followed the nonprescription products module. A report on the use of nonprescription dietary supplements for weight loss in this survey is available. ${ }^{10}$ This report is focused on respondents who had used other CAM therapies besides nonprescription supplements in the previous 12 months. Introductory comments to respondents described these therapies as "unconventional weight control therapies you have used to support you in weight loss or weight maintenance. By unconventional we mean therapies that are not typically provided by a doctor, hospital or medical clinic. These therapies are sometimes called complementary, alternative, or integrative medicine."

In naming the CAM therapy that respondents used most often in the previous year, they were instructed not to include nonprescription products (as they had previously answered questions about supplements). Therefore, for this report, CAM users were those respondents who had used any CAM therapy besides weight loss supplements as their main (most often used) CAM therapy (i.e., "Please tell me what method or therapy you used the most in the past 12 months") during the previous year. Persons who initially said "yes" to CAM use in the previous year, but who subsequently named a nonCAM method (e.g., calorie reduction, exercise) as their main (most often used) CAM method were not categorized as CAM users. Sociodemographic covariates were gender, race/ethnicity, age, income and educational level, and city size. Independent variables were: having a chronic disease ("Has a doctor ever told you that you had high blood pressure, heart disease, or diabetes?"); used exercise for weight control (“Are you using physical activity or exercise to lose weight [or keep from gaining weight?]"); ever used a low-carbohydrate, higher protein diet ("Are you currently on or have you ever been on a low-carbohydrate, higher protein diet such as Sugar Busters, The Zone, The Carbohydrate Addict's Diet, or The Atkin's Diet?"); ever used nonprescription products for weight control; body mass index category (weight in $\mathrm{kg} /$ height in meters ${ }^{2}$ : Obese, $\geq 30$, Overweight 25 to 29.9, Normal/underweight $<25$ ) ; and body size satisfaction ("How do you feel about your body size right now?" Very satisfied, Somewhat satisfied, Not satisfied). Physical activity was mea- sured with the 2001 BRFSS physical activity questions (http://www.cdc.gov/brfss/questionnaires/pdf-ques/2001 brfss.pdf), and respondents categorized based on the CDC/ American College of Sports Medicine recommendation ${ }^{11}$ as: active/meets recommendation, insufficiently active, or inactive. Respondents also reported the frequency of use for their most-used CAM therapy ("Thinking about right now, or the most recent period of time you used this method or therapy during the past 12 months, how many days, weeks, or months have you been using it or did you use it?") and the format for the therapy ("When you used this method during the past 12 months, was it done on your own, with a group or class, or with an alternative therapy practitioner? 'On your own' includes the use of videos, audiotapes, or books to guide you.")

\section{Analysis}

Data cleaning and management tasks were conducted in $2003 / 2004$ and the analysis was performed in 2004/2005. Frequencies and percentages were computed with SAS version 8.02 (SAS Institute, Cary, NC). Odds ratios were computed with SUDAAN (RTI, Research Triangle Park, NC), software that weights the data, thereby taking into account the complex sampling design, and adjusts for the under- or overrepresentation of population segments due to nonresponse. Respondents with missing data for one or more of the sociodemographic covariates or behavioral/health status predictors were excluded. Respondents who initially indicated that they had used CAM in the previous 12 months but subsequently named a mainstream weight-control method were categorized as not having used CAM in the previous 12 months. The independent variables were coded as dichotomies or trichotomies. Adjusted odds ratios were computed to determine the association between CAM use for weight control and health status or behavioral variables. Of the total completed interviews, 804 respondents were missing on one or more of the sociodemographic covariates (age, race, sex, education, and city size), and an additional 1200 were missing on one or more of the behavioral and health status variables, resulting in a sample of 9207 for the final analyses.

\section{RESULTS}

Of the 11,211 respondents, 372 respondents had used CAM for weight control in the past 12 months. Characteristics of the entire sample and for the CAM users are shown in Table 1.

Table 2 shows the most commonly used CAM therapies among respondents who had used CAM for weight control in the past 12 months. Yoga (including breathing techniques) was named by the largest proportion of respondents as their most used therapy in the previous 12 months, followed by meditation, massage, acupuncture, and Eastern martial arts (such as t'ai chi or qi gong). Other responses included hypnosis, subliminal messages, prayer, Pilates, guided imagery/visualiza- 
Table 1. Sample Characteristics

\begin{tabular}{|c|c|c|}
\hline Characteristic & 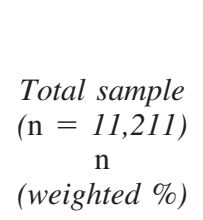 & $\begin{array}{l}\text { Have used CAM for } \\
\text { weight control in the } \\
\text { past } 12 \text { months } \\
(\mathrm{n}=372) \\
\mathrm{n} \\
\text { (weighted } \%)\end{array}$ \\
\hline \multicolumn{3}{|l|}{ Sex } \\
\hline Female & $6516(51.71)$ & $295(74.81)$ \\
\hline Male & $4695(48.29)$ & 77 (25.19) \\
\hline \multicolumn{3}{|l|}{ Race/ethnicity } \\
\hline White, non-Hispanic & $7512(70.85)$ & $266(76.24)$ \\
\hline Black, non-Hispanic & $1346(10.88)$ & $34(4.63)$ \\
\hline Hispanic & $1573(10.62)$ & $46(10.08)$ \\
\hline All others & $564(5.84)$ & $27(8.31)$ \\
\hline Don't know/refused/missing & $216(1.82)$ & $3(0.75)$ \\
\hline \multicolumn{3}{|l|}{ Age, y } \\
\hline $18-34$ & $3160(31.36)$ & $154(45.83)$ \\
\hline $35-54$ & $4437(38.73)$ & $151(38.69)$ \\
\hline $55-99$ & $3359(27.71)$ & $61(14.19)$ \\
\hline Missing/refused & $255(2.20)$ & $6(1.29)$ \\
\hline \multicolumn{3}{|l|}{ Income } \\
\hline$\geq \$ 50,000$ & $3628(36.27)$ & $142(43.93)$ \\
\hline$\$ 25,000-\$ 49,999$ & $3291(28.64)$ & $109(26.12)$ \\
\hline$\leq \$ 24,999$ & $2705(20.91)$ & $77(17.17)$ \\
\hline Don't know/refused & $1587(14.71)$ & $44(12.77)$ \\
\hline \multicolumn{3}{|l|}{ Education } \\
\hline$>$ High school & $1314(10.97)$ & $19(4.40)$ \\
\hline High school graduate & $3048(27.14)$ & $61(18.94)$ \\
\hline Some college/technical school & $3002(27.45)$ & $106(29.69)$ \\
\hline College graduate & $3762(33.61)$ & $185(46.71)$ \\
\hline Refused & $85(0.83)$ & $1(0.26)$ \\
\hline \multicolumn{3}{|l|}{ City size } \\
\hline Large city $(>100,000$ people $)$ & $4217(36.36)$ & $169(44.44)$ \\
\hline Smaller city $(30,000-100,000$ people $)$ & $2784(25.11)$ & $91(22.35)$ \\
\hline Rural city (1000-2999 people) & $2247(20.96)$ & $65(20.16)$ \\
\hline Small community/village $(<1000$ people $)$ & $1520(13.85)$ & $38(10.87)$ \\
\hline Don't know/not sure/refused & $443(3.72)$ & $9(2.18)$ \\
\hline
\end{tabular}

CAM, complementary and alternative medicine.

tion/affirmation, chiropractic, light therapy, colon cleansing, and energy healing. Responses among persons who could name a second $(n=93)$ and third $(n=25)$ most-often-used CAM therapy for weight control named the same top five as shown in Table 2 for the primary therapy. Among the 372 respondents, 363 respondents estimated the number of days they had used the primary method. The mean number of days of use in the previous 12 months was 146 (standard deviation = 140), with a range of 1-365 days and median of 93 days. The modes of delivery for the primary CAM weight control therapy were on one's own (including videotapes, audiotapes, or books for guidance) $(62.6 \%)$, in a group or class setting (26.8\%), and from a CAM practitioner (10.6\%).

Table 3 shows adjusted odds ratios for CAM use for weight control in the past 12 months for several behavioral and health status variables, adjusted for age, race, gender, education, and city size. The odds ratios were not adjusted for income because $14 \%$ of respondents either refused to answer or did not know their income.
Using exercise for weight control at the time of the interview; ever using a lower carbohydrate, higher protein diet; ever using a nonprescription weight loss product; being overweight; being active: either active/meets the guideline or insufficiently active to meet the guideline; and not being satisfied with one's body were associated with significantly higher odds of using CAM for weight control in the past 12 months. Self-rated general health (excellent to poor) $(p=0.53)$ and having a diagnosis of heart disease, diabetes, or high blood pressure (yes, no) $(p=.64)$ were not significantly associated with CAM use in the past 12 months, and these data are not shown in the Table 3.

\section{DISCUSSION}

The NPAWLS is the first survey to assess dietary behavior, physical activity, weight-control behavior, and CAM use in a large national sample, with sampling techniques to 
Table 2. CAM Therapies Used Most Often for Weight $\operatorname{ConTROL}^{\mathrm{a}}(N=372)$

\begin{tabular}{lrc}
\hline Therapy & $\mathrm{n}$ & Weighted \% \\
\hline Yoga & 208 & 57.40 \\
Meditation & 33 & 8.18 \\
Massage & 25 & 7.46 \\
Acupuncture & 22 & 7.74 \\
Eastern martial arts & 20 & 5.88 \\
All other CAM therapies combined & 64 & 13.34 \\
\hline
\end{tabular}

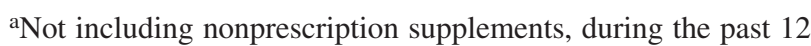
months.

CAM, complementary and alternative medicine.

ensure large numbers of Hispanic and black/African American respondents. A strength of the study is that respondents were asked to name their primary CAM method for weight control, so that their responses could be coded and any mainstream methods misreported as CAM could be eliminated. Even when the interviewer provided a definition of CAM, $70 \%$ of respondents who initially said they had used CAM in the previous 12 months named a therapy that reasonably could be considered CAM, whereas the remaining 30\% named a mainstream approach such as calorie or fat restriction or exercise. Other strengths of the study are that the survey was conducted in both English and Spanish and used a population-based sample rather than a convenience sample. The broad range of dietary, weight control, and physical activity behaviors asked about in the survey made possible an examination of associations between these lifestyle behaviors and CAM use for weight control.

A limitation of the study is the relatively low CASRO response rate of $30 \%$. This rate was partially because of the survey design, which mixed telephone numbers from three independent samples to achieve racial/ethnic target proportions for Hispanic and non-Hispanic black respondents. Pretargeting of ethnic groups, which is not done by the BRFSS, increases the number of phone calls that are made to urban minority areas. Although this approach oversampled minority groups to increase the number of participants in these strata and to allow for subgroup analyses, these subgroups had low response rates and therefore the overall response rate is lower than one might expect to get in a random sample. Increasing cellular phone use and avoidance of suspected telemarketing calls may have negatively affected the response rate. Although the response rate was lower than optimal, this was unlikely to result from any particular characteristic of the NPAWLS questions, topics, or methods. Response rates for all types of surveys have shown a widespread decline in recent years. ${ }^{12}$ When contact was successful and eligibility could be determined, the cooperation rate was $51.4 \%$.

Table 3. Significant Adjusted Bivariate Associations with Use of CAM for Weight Control $(N=9207)$

\begin{tabular}{|c|c|c|c|c|c|c|}
\hline \multirow[b]{2}{*}{ Behavioral and attitudinal variables } & \multirow[b]{2}{*}{$\mathrm{n}$} & \multirow[b]{2}{*}{$\begin{array}{c}\text { Weighted \% } \\
\text { for total } \\
\text { sample }\end{array}$} & \multirow[b]{2}{*}{$\begin{array}{l}\text { Adjusted \% } \\
\text { Used CAM } \\
\text { past } 12 \mathrm{mo}\end{array}$} & \multicolumn{3}{|c|}{ Used CAM in the past 12 months } \\
\hline & & & & $\begin{array}{c}\text { AOR } \\
\text { Used CAM } \\
\text { past } 12 \mathrm{mo}\end{array}$ & $95 \% C I$ & $\mathrm{p}$ value \\
\hline \multicolumn{7}{|l|}{ Used exercise for weight control } \\
\hline Yes & 3966 & 42.5 & 5.2 & 2.71 & $1.99,3.69$ & $<0.0001$ \\
\hline No or not controlling weight & 5241 & 57.5 & 2.0 & 1.00 & & \\
\hline \multicolumn{7}{|c|}{ Ever used lower carbohydrate/higher protein diet } \\
\hline Yes & 1287 & 13.4 & 5.4 & 1.75 & $1.26,2.43$ & 0.0008 \\
\hline No & 7920 & 86.6 & 3.2 & 1.00 & & \\
\hline \multicolumn{7}{|c|}{ Ever used nonprescription product for weight control } \\
\hline Yes & 1664 & 17.7 & 5.2 & 1.77 & $1.31,2.38$ & 0.0002 \\
\hline No & 7543 & 82.3 & 3.1 & 1.00 & & \\
\hline \multicolumn{7}{|l|}{ Body Mass Index category } \\
\hline Obese $(\geq 30)$ & 1957 & 20.9 & 3.8 & 1.35 & $0.93,1.96$ & 0.1106 \\
\hline Overweight (25 to 29.9 ) & 3309 & 36.6 & 4.5 & 1.63 & $1.19,2.22$ & 0.0022 \\
\hline Normal/underweight $(<25)$ & 3941 & 42.5 & 2.9 & 1.00 & & \\
\hline \multicolumn{7}{|c|}{$\begin{array}{l}\text { Physical activity level (CDC/ACSM recommendation } \\
\text { for moderate or vigorous physical activity) }\end{array}$} \\
\hline Active, meets guideline & 4396 & 49.0 & 4.5 & 5.68 & $2.82,11.45$ & $<0.0001$ \\
\hline Insufficiently active & 3562 & 38.3 & 2.9 & 3.52 & $1.73,7.19$ & 0.0005 \\
\hline Inactive & 1249 & 12.7 & 0.9 & 1.00 & & \\
\hline \multicolumn{7}{|l|}{ Body satisfaction } \\
\hline Not satisfied & 1735 & 18.0 & 4.6 & 1.56 & $1.04,2.33$ & 0.0318 \\
\hline Somewhat satisfied & 4370 & 48.5 & 3.4 & 1.15 & $0.84,1.56$ & 0.3889 \\
\hline Very satisfied & 3102 & 33.5 & 3.0 & 1.00 & & \\
\hline
\end{tabular}

Note: Models were adjusted for age, gender, race, education, and city size.

CAM, complementary and alternative medicine; AOR, adjusted odds ratio; CDC, Centers for Disease Control and Prevention; ACSM, American College of Sports Medicine. 
Another limitation of the study is that not all of the questions addressed the same time frame. Some questions did not address a specific time frame or addressed the present, whereas others referred to "ever" or to the past 12 months. This temporal issue, combined with the cross-sectional nature of the survey, prevents drawing conclusions about causal associations between the behavioral and health status variables and use of CAM therapies for weight control. Additionally, there are likely to be other behavioral, social, and health status variables associated with CAM use for weight control that were not included in the NPAWLS questionnaire.

This report provides new information about CAM use for weight control in a very large sample of U.S. adults. The results show that people who had engaged in other weight control behaviors were more likely to have used CAM in the previous 12 months, a finding that suggests people may be using physical activity, lower carbohydrate/ higher protein diets, and nonprescription weight loss products in conjunction with other CAM methods for weight control, or trying them one after the other. This pattern may indicate persistent unsuccessful attempts to lose weight by multiple methods. Although overweight persons had increased odds for using CAM for weight control in the past 12 months, it is of interest to note that of the 372 persons who had used CAM for weight control in the previous year, 156 (weighted $\%=42.56$ ) were not overweight or obese according to their BMI, as calculated from self-reported weight and height.

\section{CONCLUSIONS}

Only 3\% (weighted) of the total respondents had used CAM for weight control in the previous 12 months; 5\% (weighted) of respondents who were trying to lose weight at the time of the interview had done so. These results indicate that the use of CAM therapies for weight loss, other than nonprescription supplements, is relatively low. The method of choice by far was yoga, trailed by meditation, massage, acupuncture, and Eastern martial arts as the top five. Neither the potential direct effects of these methods on weight control, nor the potential indirect effects (e.g., stress reduction attained via these therapies might aid in dietary adherence) have been adequately investigated. Consequently, the effectiveness of these methods for weight loss is unknown.

\section{ACKNOWLEDGMENTS}

The authors appreciate the assistance of Heather Bowles, Ph.D., Brent Hutto, M.S.P.H., Lara Peck, M.P.H., and Deborah Jones, Ph.D., in the preparation of the manuscript. This research was funded by a cooperative agreement from the Centers for Disease Control and Prevention (Atlanta, GA)
(U48/CCU409664) to the University of South Carolina Prevention Research Center (Columbia, SC). The contents of this report are solely the responsibility of the authors and do not necessarily represent the official views of the Centers for Disease Control and Prevention.

\section{REFERENCES}

1. National Center for Complementary and Altenative Medicine. What is complementary and alternative medicine? Online document http://nccam.nih.gov. Accessed July 28, 2004.

2. Barnes PM, Powell-Griner E, McFann K, Nahin RL. Complementary and alternative medicine use among adults: United States, 2002. Adv Data 2004;343:1-19.

3. Neal R. Report by David M. Eisenberg, M.D., on complementary and alternative medicine in the United States: Overview and patterns of use. J Altern Complement Med 2001;7:S19-S21.

4. Bausell RB, Wen-Lin L, Berman BM. Demographic and health-related correlates of visits to complementary and alternative medical providers. Med Care 2001;39:190-196.

5. Eisenberg DM, Kessler RC, Van Rompay MI, et al. Perceptions about complementary therapies relative to conventional therapies among adults who use both: Results from a national survey. Ann Intern Med 2001;135:344-351.

6. Blanck HM, Khan LK, Serdula MK. Use of nonprescription weight loss products: Results from a multistate survey. JAMA 2001;286:930-935.

7. Pittler MH, Ernst E. Dietary supplements for body-weight reduction: A systematic review. Am J Clin Nutr 2004;79: 529-536.

8. Allison DB, Fontaine KR, Heshka S, et al. Alternative treatments for weight loss: A critical review. Crit Rev Food Sci Nutr 2001;41:1-28.

9. Frankel LR. The report of the CASRO Task Force on Response Rates. In: Wiseman F, ed. Improving Data Quality in a Sample Survey. Cambridge, MA: Marketing Science Institute, 1983.

10. Blanck HM, Serdula MK, Gillespie C, et al. Use of nonprescription dietary supplements for weight loss is common among Americans. J Am Diet Assoc 2007;107:441-447.

11. Pate RR, Pratt M, Blair SN, et al. Physical activity and public health. A recommendation from the Centers for Disease Control and Prevention and the American College of Sports Medicine. JAMA 1995;273:402-407.

12. Tourangeau R. Survey research and societal change. Ann Rev Psychol 2004;55:775-801.

Address reprint requests to: Patricia A. Sharpe, Ph.D.

Prevention Research Center Arnold School of Public Health University of South Carolina 730 Devine Street Columbia, SC 29208

E-mail: pasharpe@sc.edu 


\section{This article has been cited by:}

1. Wei He, Zhongyu Zhou, Jiakang Li, Lu Wang, Bing Zhu, Gerhard Litscher. 2012. Auricular Acupressure Plus Exercise for Treating Primary Obese Women: A Randomized Controlled Clinical Trial. Medical Acupuncture 24:4, 227-232. [Abstract] [Full Text HTML] [Full Text PDF] [Full Text PDF with Links]

2. Nangel M. Lindberg, Victor J. Stevens, Charles Elder, Kristine Funk, Lynn DeBar. 2012. Use of Alternative Medicine for Weight Loss Among Mexican-American Women. Journal of Immigrant and Minority Health . [CrossRef]

3. Charles R Elder, Christina M Gullion, Lynn L DeBar, Kristine L Funk, Nangel M Lindberg, Cheryl Ritenbaugh, Gayle Meltesen, Cherri Gallison, Victor J Stevens. 2012. Randomized trial of tapas acupressure technique for weight loss maintenance. $B M C$ Complementary and Alternative Medicine 12:1, 19. [CrossRef]

4. Bin Bu, Han Haijun, Liu Yong, Zhang Chaohui, Yang Xiaoyuan, Maria Fiatarone Singh. 2010. Effects of martial arts on health status: A systematic review. Journal of Evidence-Based Medicine 3:4, 205-219. [CrossRef]

5. Charles Elder, Cherri Gallison, Nangel M. Lindberg, Lynn DeBar, Kristine Funk, Cheryl Ritenbaugh, Victor J. Stevens. 2010. Randomized Trial of Tapas Acupressure Technique ${ }^{\circledR}$ for Weight Loss Maintenance: Rationale and Study Design. The Journal of Alternative and Complementary Medicine 16:6, 683-690. [Abstract] [Full Text HTML] [Full Text PDF] [Full Text PDF with Links]

6. Alyson Ross, Sue Thomas. 2010. The Health Benefits of Yoga and Exercise: A Review of Comparison Studies. The Journal of Alternative and Complementary Medicine 16:1, 3-12. [Abstract] [Full Text HTML] [Full Text PDF] [Full Text PDF with Links]

7. T. Togo, S. Urata, K. Sawazaki, H. Sakuraba, T. Ishida, K. Yokoyama. 2010. Demand for CAM Practice at Hospitals in Japan: A Population Survey in Mie Prefecture. Evidence-based Complementary and Alternative Medicine . [CrossRef]

8. Junghyun Kim, Dae Sik Jang, Hyojun Kim, Jin Sook Kim. 2009. Anti-lipase and lipolytic activities of ursolic acid isolated from the roots of Actinidia arguta. Archives of Pharmacal Research 32:7, 983-987. [CrossRef]

9. Chung-Hua Hsu, Chi-Jung Wang, Kung-Chang Hwang, Tzung-Yan Lee, Pesus Chou, Hen-Hong Chang. 2009. The Effect of Auricular Acupuncture in Obese Women: A Randomized Controlled Trial. Journal of Women's Health 18:6, 813-818. [Abstract] [Full Text PDF] [Full Text PDF with Links]

10. Terrence E. Steyer, Adrienne Ables. 2009. Complementary and Alternative Therapies for Weight Loss. Primary Care: Clinics in Office Practice 36:2, 395-406. [CrossRef]

11. S JEONG, K CHAE, Y JUNG, Y RHO, J LEE, J HA, K YOON, G KIM, K OH, S SHIN. 2008. The Korean traditional medicine Gyeongshingangjeehwan inhibits obesity through the regulation of leptin and PPAR $\alpha$ action in OLETF rats. Journal of Ethnopharmacology 119:2, 245-251. [CrossRef]

12. Jinmi Lee, Kyungsil Chae, Juran Ha, Byung-Young Park, Hee Suk Lee, Sunhyo Jeong, Min-Young Kim, Michung Yoon. 2008. Regulation of obesity and lipid disorders by herbal extracts from Morus alba, Melissa officinalis, and Artemisia capillaris in highfat diet-induced obese mice. Journal of Ethnopharmacology 115:2, 263-270. [CrossRef]

13. James S. Lin. 2007. Prevalence of CAM Use Includes Patients of Asian Background. The Journal of Alternative and Complementary Medicine 13:6, 594-596. [Citation] [Full Text PDF] [Full Text PDF with Links]

14. Eran Ben-Arye, Ilan Katz, Ohad Hochman, Doron Hermoni. 2007. Exploring Feldenkreis Practitioners' Attitudes Toward Clinical Research. The Journal of Alternative and Complementary Medicine 13:6, 593-594. [Citation] [Full Text PDF] [Full Text PDF with Links] 